\title{
A Novel Approach to Site Selection: Collaborative Multi-Criteria Decision Making through Geo-Social Network (Case Study: Public Parking)
}

\author{
Zeinab Neisani Samani ${ }^{1, *}$, Mohammad Karimi ${ }^{2}$ and Ali Asghar Alesheikh ${ }^{2}$ \\ 1 Department of RS/GIS, Science and Research Branch, Islamic Azad University, Tehran 14778 93855, Iran \\ 2 Department of GIS, Faculty of Geodesy and Geomatics Engineering, K. N. Toosi University of Technology, \\ Tehran 19967 15433, Iran; mkarimi@kntu.ac.ir (M.K.); alesheikh@kntu.ac.ir (A.A.A.) \\ * Correspondence: zeinab.neisani@srbiau.ac.ir; Tel.: +98-21-4486-1784
}

Received: 29 November 2017; Accepted: 17 February 2018; Published: 1 March 2018

\begin{abstract}
There are many potential factors that are involved in the decision making process of site selection, which makes it a challenging issue. This paper addresses the collaborative decision making concept through a geo-social network to predict site selection for public parking in Tehran, Iran. The presented approach utilized the analytic hierarchy process (AHP) as a multi-criteria decision method (MCDM) for weighting the criteria, which was completed in two stages; once by 50 experts, and then by three different levels of users, including 50 experts, 25 urban managers, and 150 pubic citizens, with respect to the case study area. The fuzzy majority method aggregates the archived results of AHP to determine the preferred locations that are suitable for public parking. The proposed method was implemented using a telegram bot platform. Two main advantages of the collaborative decision making scenario for public urban site selection are the fair distribution of the selected locations and the high satisfaction of users, which increased from $65 \%$ to $85 \%$. This study presents an application for site selection based on multi-criteria decision making in a geo-social network context.
\end{abstract}

Keywords: site selection; MCDM; fuzzy majority; geo-social network; public parking; collaborative decision making

\section{Introduction}

Site selection is one of the basic decisions in a public urban space that can be determined based on topographic interest, land availability, land use, and public preference [1]. The site needs to be free of any natural or environmental interference, undesirable industry, business, or traffic hazards, and it needs be accessible to present and future populations. In most communities, however, the most favorable site is elusive to find [2,3]. Traditionally, site selection relied on an expert's knowledge, while the main users of the facilities, such as urban managers and especially public citizens, were not included [4]. Thus, the locations of selected areas do not meet user's interests and requirements [5]. One of the most important urban facilities is public parking. Today, due to the widespread use of the automotive, almost all large cities experience public parking unavailability. In fact, one of the issues that comes up to solve the traffic problem is the right choice for public parking [6,7]. Therefore, it is necessary to study a previous approach to obtain the most advantageous site selection for public parking.

Site selection for urban facilities has been studied for many years. The American Institute of Transportation Engineers gave a summary of different cities in some countries in the USA Continent, the UK and Asia. They found that the accessory parking ratio was proportional to the urban transportation system and car ownership rate [8]. The study by Boroushaki and Malczewski (2010) described Web-Based Collaborative Spatial Decision making and Participatory GIS as a proof of 
concept. They discussed the potential of the Internet to facilitate collaborative, spatial decision making. Moreover, they considered the fuzzy majority method using Induced Ordered Weighted Averaging (IOWA) for spatial group decision-making. As a result, these multi-criteria decision analysis (MCDA) methods provide a mechanism for bridging the gap between public residents and experts. However, the technological limitations in developing countries can be found [9]. Parker et al. (2013) integrated Volunteer Geographic Information (VGI) and Participatory GIS (PGI) in an outdoor recreation context. They demonstrated that both VGI and PGI have a greater ability to influence the user in the planning phase than during the activity [10].

Li et al. (2014) studied the users' actions, which was modeled based on a new type of Spatial-aware Interest Group query that retrieves a user group, where each user is interested in the query keywords and they are close to each other in Euclidean space [11]. Malczewski and Rinner (2015) investigated a collaborative multivariable decision analysis for students who are practitioners in different fields of GIScience [12]. Hong (2015) analyzed the spatial patterns of Location-Based Social Network (LBSN) data in Seoul using spatial analysis techniques of a geographic information system. The data were compiled with a schema that was produced based on Foursquare's Python API. Based on the analytical results, the researcher were able to identify venue clusters around city centers, as well as differences in hotspots for various venue categories and correlations with census variables [13].

Levy et al. (2015) presented ParkFit, which is defined as a spatially-explicit high-resolution view of urban parking supply and demand. As a practical setting, ParkFit has its own limitations. For example, one must establish the maximal acceptable distance for parking, which could be far away from one's destination. Second, this model cannot incorporate parking search times, price, and turn over, local factors of driver's favorable spot, security, and road crossings during the walk [14]. The Abbasi et al. (2017) study investigated the potential of LBSN data alongside the rank concept in predicting human mobility patterns in Manhattan, New York City. They suggest three scenarios, including rank-distance, the number of venues between origin and destination, and a check-in weighted inception schema. In this study, applying a check-in weighting schema to trip distribution patterns resulted in a sample that was little approximately more similar to the ground truth data. As the predicted numbers of trips were closer to the real number of trips, trip distribution was also increased by about $50 \%$ [15].

Recently, Krieg et al. (2018) presented Smart Park, a system for real-time parking information relying on smartphone sensors and a ubiquitous Wi-Fi/cellular infrastructure. Experimental results from 12 volunteers revealed that Smart Park identified unparking events $97 \%$ of the time, while triggering zero false positives. While Smart Park uses simulations to minimize the initial deployment cost and risk, it fails to detect unparking events when the distance between two cars is $10 \mathrm{~m}$ or less [16]. Here, we demonstrate the incorporation of multi decision makers based on geo-social network to optimize an urban public site selection in Tehran, which is the most populated city in Iran.

As a practical setting for model development, we assess the problem of selecting sites for public parking. Section 2 presents the Analytic Hierarchy Process as a GIS-based multi-criteria decision analysis (MCDA). Then, the related concepts and the detailed analysis are demonstrated in Section 3. Finally, conclusions and directions of potential future research are considered in Section 4.

\section{Materials and Methods}

Our design consists of three parts. In the first part, we use AHP to plan site selection using multi-criteria decision making analysis. Then, we consider the geo-social network as a platform for handling different views. Finally, the proposed model and its characteristics are illustrated.

\subsection{Site Selection and Multi-Criteria Decision Analysis}

Formerly, site selection was based entirely on economic and technical criteria. Selection criteria must also please social and environmental requirements, which are enforced by legislation and government regulations. Nowadays, in the post-industrial and knowledge-based society, people 
become the most important resource. The process of site selection needs complex multi-criteria analyses, which include an array of factors involving economic, social, technical, environmental, and political issues that may result in conflicting objectives [17]. GIS-based multi-criteria decision analysis (MCDA) is a set of techniques for solving spatial problems by considering and weighting different criteria (i.e., geographical features) in the decision making process [3,18].

The MCDA issue ordered support including multi-objective decision analysis (MODA) for multi-attribute decision making (MADA), individual for group decision-maker, and decision under confidence for decision under confidence. Decision making is relying on spatial data, information and communication technologies. It is used by managers and decision-makers to exchange opinions and information, which is a requisite when focusing on specific decision topics. Spatial decisions considered on the basis of multiple criteria [3].

\subsection{Geo-Social Networks}

The worldwide progress in universal relations, computer networks, and location-based services has introduced a novel trend in Geographic information system. Geo-social networks as integrating systems of mobile devices, wireless networks, and other GIS capabilities have developed in the geographic information system scope $[19,20]$. In fact, technological progress has led to an increasing expansion of data sources. Since the innovation of social networks, numerous studies about users' activities have been executed.

The dimension of place helps link the gap between the physical world and virtual social networking services [21]. On the other hand, public participation activities utilized from geo-social networks capabilities are used to solve urban spatial problems [11,22].

In addition, it is an appropriate platform for collaboration among public citizens, urban experts, and governmental managers. However, this collaboration was not mentioned for site selection of public facilities until now. Users are always in their area of residence and activity and they use suitable site to structure the environment and to support urban services [23].

\subsection{Proposed Method}

This paper tries to solve the urban site selection problem using participatory GIS through geo-social networks. In this way, the proposed methodology is designed as shown in Figure 1.

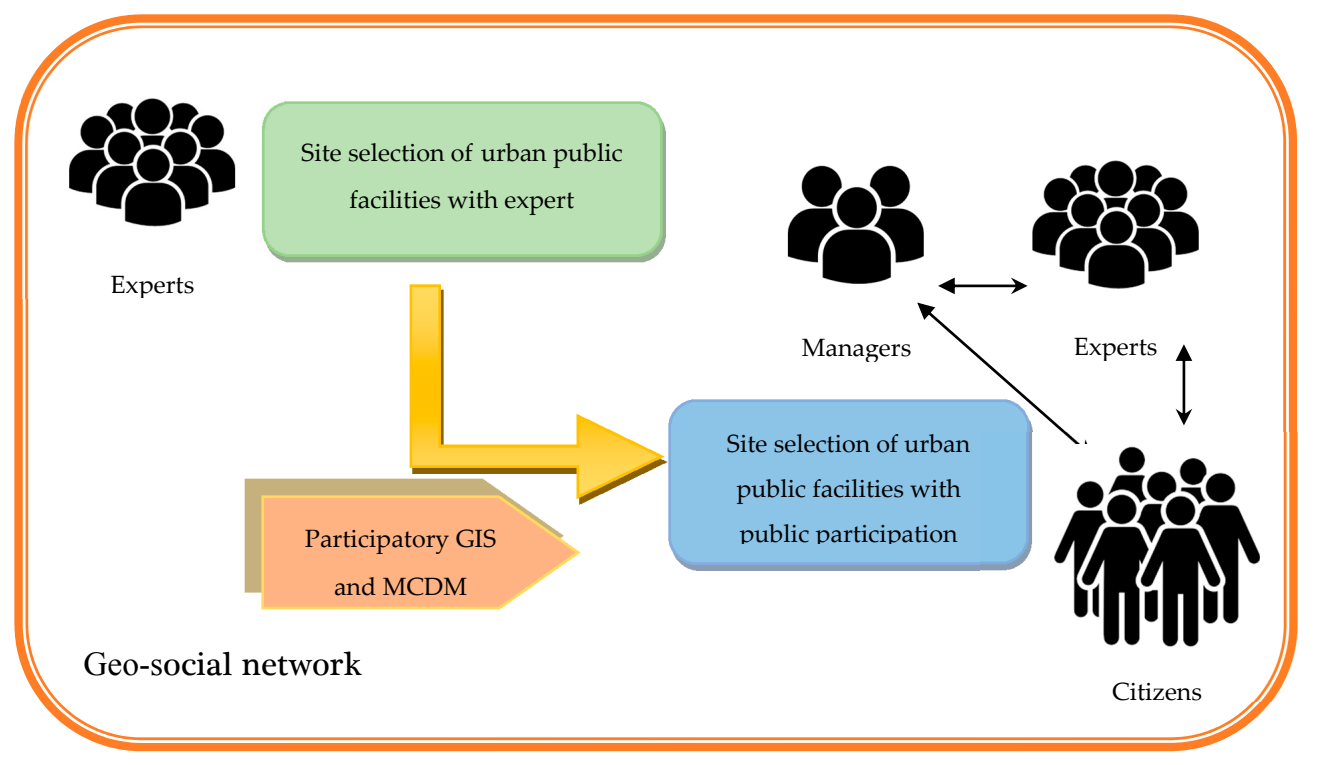

Figure 1. Collaborative decision making for public urban site selection. 
A Geographic Information System (GIS) is a basic part of modelling technology for urban data management and analysis. Therefore, integration of GIS with other methods makes it possible to model most of the MCDM approach [24].

Step\#1: This step is concentrated on the selection of dominant criteria, which have an effect on the determination of appropriate public parking in an urban area. To achieve this, we selected five criteria: Population density, traffic congestion, access, land value, and width of street. Among these criteria, "access" has sub-criteria, as illustrated in Figure 2.

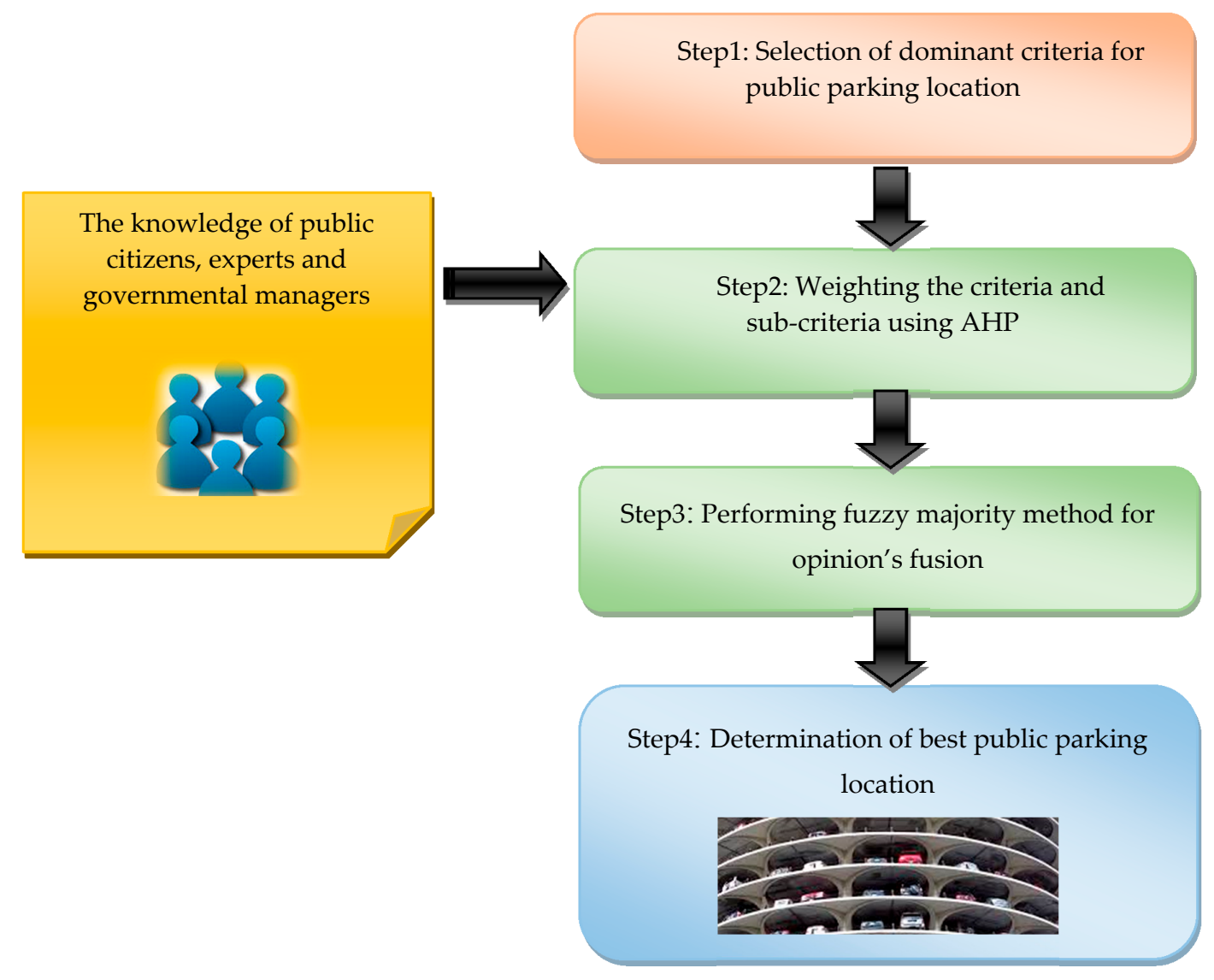

Figure 2. The conceptual framework of the proposed methodology.

Step\#2: Weighting of the defined criteria is an important stage and the reliability of its consequences could guarantee the final results. The weighting of the criteria is done by AHP. The AHP method is based on paired weighting. The geometric mean method was used to calculate the weight of the factors. The next step in this process is to estimate the incompatibility ratio. This probability value represents the probability of corresponding random degrees, so that values of less than 0.1 are good, values that are worth more than 0.1 are incompatible, and the weighting of the criteria should be re-established [18,24]. With the use of the AHP method in this study, the hierarchy of criteria for locating public parking was in accordance with Figure 3. 


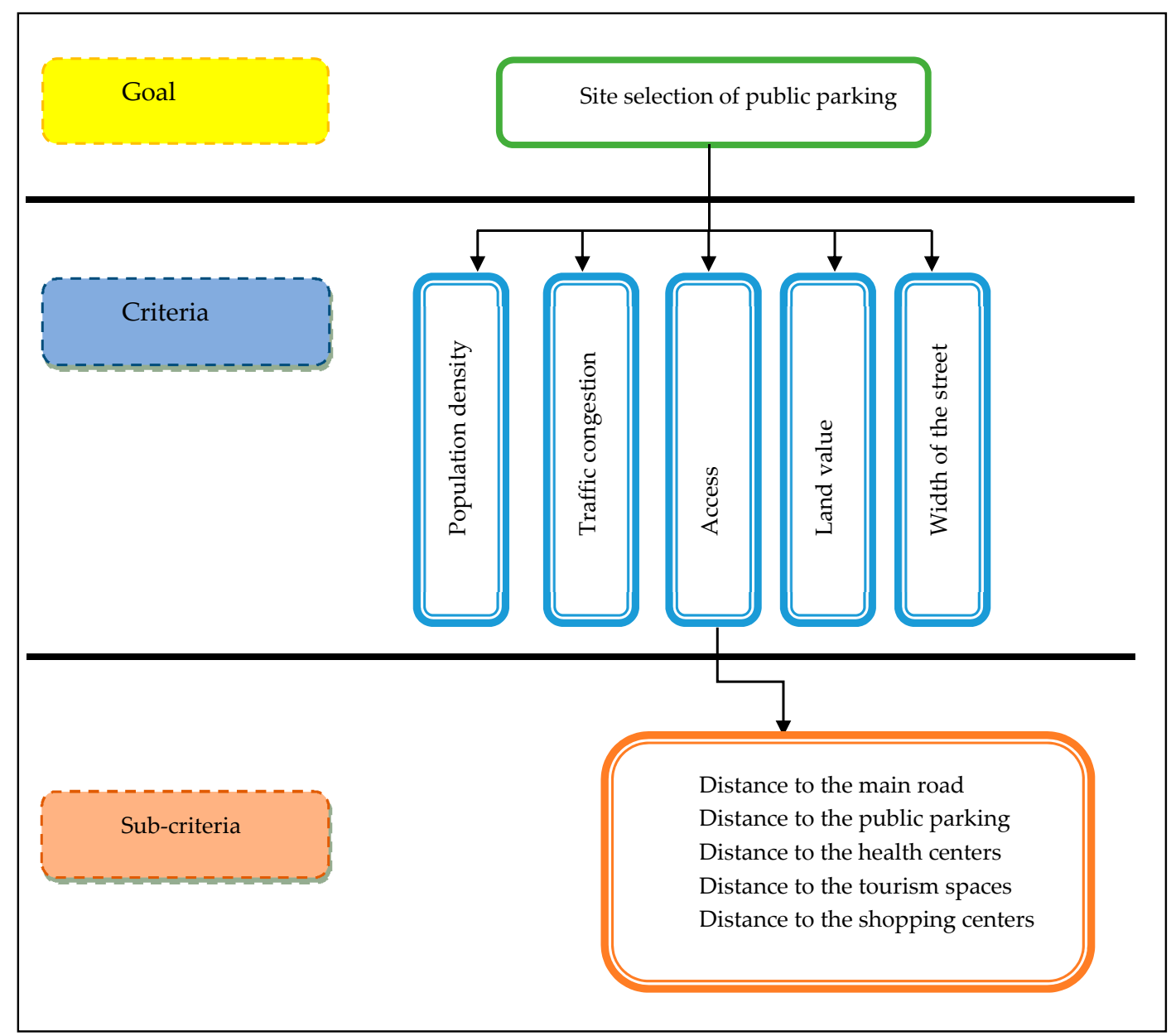

Figure 3. Hierarchy of criteria.

Step\#3: In order to aggregate the opinions of the different levels of decision-makers, the fuzzy majority approach is applied. The fuzzy majority is an aggregation procedure that through preference incorporates the opinion of the majority of decision-makers. The ultimate aggregated amount characterizes the value of the majority of the most similar amounts. The similarities between pairs of preference values can be computed using a support function, $\operatorname{Sup}(a, b)$, which can be denoted as the support for ' $a$ ' from ' $b$ ' where [25]:

$$
\operatorname{Sup}(a, b) \geq \operatorname{Sup}(x, y) \text { if }|a-b|<|x-y|,
$$

Therefore, the closer two argument values are, the more that they support each other [26]. In addition, the most supported values have more weight in the aggregation method. They demonstrated that the fuzzy majority procedure produces the majority semantic of preferences in a group decision-making process [25].

The score of using OWA achieved for each proposed option that defined as $P^{k}(\mathrm{k}$ is decision-makers no). The problem can be defined as $\left[P_{i}^{1}, P_{i}^{2}, \ldots, P_{i}^{q}\right] \rightarrow P_{i}^{\text {majority }}$, which denotes the aggregation of the set preferences $P_{i}^{k}$ in such a way that the final score corresponds to the majority of the preferences values. This problem can be solved by considering all of the $k$ values. The following steps are:

Calculating the total value support for the $k$ th decision-maker's preference from other decision-makers on the $i$ th alternative is as follows: 


$$
\mathrm{t}_{\mathrm{k}}=\sum_{d=1}^{q} \operatorname{Sup}\left(P_{i}^{k}, P_{i}^{d}\right)
$$

The $\operatorname{Sup}\left(P_{i}^{k}, P_{i}^{d}\right)$ is a binary support operation as:

$$
\operatorname{Sup}\left(P_{i}^{k}, P_{i}^{d}\right)=\left\{\begin{array}{ll}
1 & \text { if }\left|P_{i}^{k}-P_{i}^{d}\right|<\alpha \\
0 & \text { if }\left|P_{i}^{k}-P_{i}^{d}\right| \geq \alpha
\end{array},\right.
$$

Here, weight $P^{k}$ is calculated using OWA (or other forms of decision). ' $\alpha$ ' is a threshold in the support function.

According to the support function, $\operatorname{Sup}\left(P_{i}^{k}, P_{i}^{d}\right)$, two values support each other if the proximity or distance between the two values is less than ' $\alpha$ '; otherwise, they provide no support. In this setting, ' $\alpha$ ' defines the threshold by which the proximity of the values is considered supportive (close enough) or not (). By summing these values up in each row, the number $t^{\prime}{ }_{k}$ the second stage of this sort in ascending order numbers $\mathrm{t}_{\mathrm{k}}^{\prime}$ and $\mathrm{t}_{1}{ }_{1} \leq \mathrm{t}_{2}{ }_{2} \leq \ldots \leq \mathrm{t}_{\mathrm{q}}{ }_{\mathrm{q}}$ is named. Define ' $\mathrm{Q}$ most' is as fuzzy membership function that is calculated according to the following steps:

$$
\mathrm{Q}^{\prime} \text { most }^{\prime}(\mathrm{x})=\left\{\begin{array}{cc}
1, & x \geq 0.8 \\
2 x-0.6 & 0.3<x<0.8 \\
0, & x \leq 0.3
\end{array},\right.
$$

After calculating the value of ' $Q$ ', $V_{k}$ is achieved according to Equation (8) by dividing each value of ' $Q$ ' by the total column values ' $Q$ ':

$$
V_{k}=\frac{Q\left(\frac{t^{\prime} k}{q}\right)}{\sum_{k=1}^{q} Q\left(\frac{t^{\prime} k}{q}\right)},
$$

Calculating the OWA score for each $i$ th location, $A_{i}$, corresponding to the majority of the decision-makers' preferences as follows:

$$
P_{i}^{\text {majority }}=O \mathrm{OWA}_{i}\left(P_{i}^{1}, P_{i}^{2}, \ldots, P_{i}^{q}\right)=\sum_{k=1}^{q} V_{k} \cdot P_{i}^{t-i n d e x(k)},
$$

where $t$-index $(k)$ is the $k$ th 'smallest'.

Step\#4: After the aggregation process, the final appropriate locations are determined and evaluated.

\section{Results}

This section explains the implementation process. First, the case study area is introduced and the required data are illustrated. Second, the system architecture is explained. Finally, the results of the implementation are discussed.

\subsection{Study Area}

Tehran district 6 Municipality has an area of 2138.5 hectares and comprises 3.3\% of Tehran's metropolis. In the north of this area is District 3 (Hemmat Expressway), to the east is District 7 (Modares Expressway), to the west is District 2 (Chamran Expressway), and to the south are Districts 10, 11, 12, and (Enghelab Av), which includes six regions and 18 local areas.

Figure 4 shows the geographical position of the study area. According to the latest statistics obtained, the population of District 6 is about 237,292 people, of which 119,421 are men and 117,871 are women [27]. 


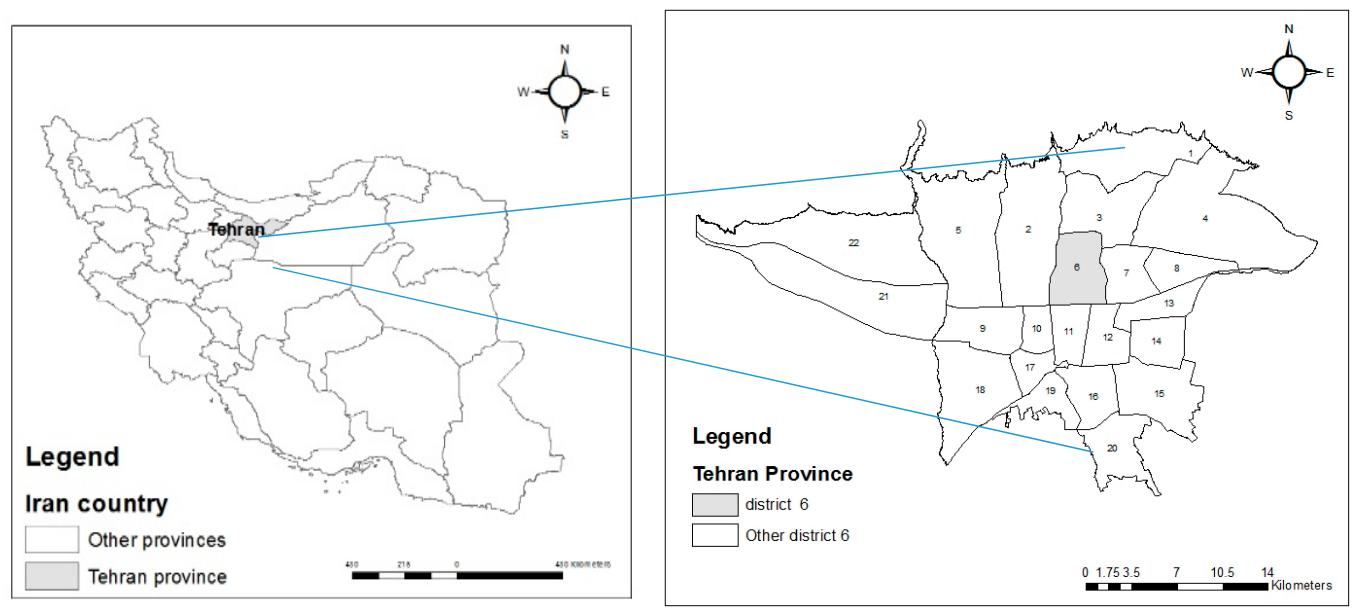

Figure 4. The geographical position of the study area.

\subsection{Required Data}

As described in Section 3, the main criteria include population density, traffic congestion, land value, width of the street, and access (which consists of distance from public parking, tourist centers, main roads, heath centers, and shopping centers). The first step in implementation is the preparation of required data, as described in Table 1.

Table 1. Data for the main criteria.

\begin{tabular}{cc}
\hline Criteria & Description \\
\hline Traffic congestion & Navigational graph in 1:2000 \\
Population density & Statistical blocks of the region \\
Value of the land & Value of each land parcel; 1:2000 urban maps \\
Width of the street & Navigational graph in 1:2000 \\
Access & Derived from 1:2000 navigation graph \\
\hline
\end{tabular}

\subsection{System Architecture}

In this research, the telegram social network was used as a platform for decision making in the spatial group. Telegram is user-friendly and open source software that has a high security level. The architecture of the proposed system is generally designed in three physical layers, as shown in Figure 5.

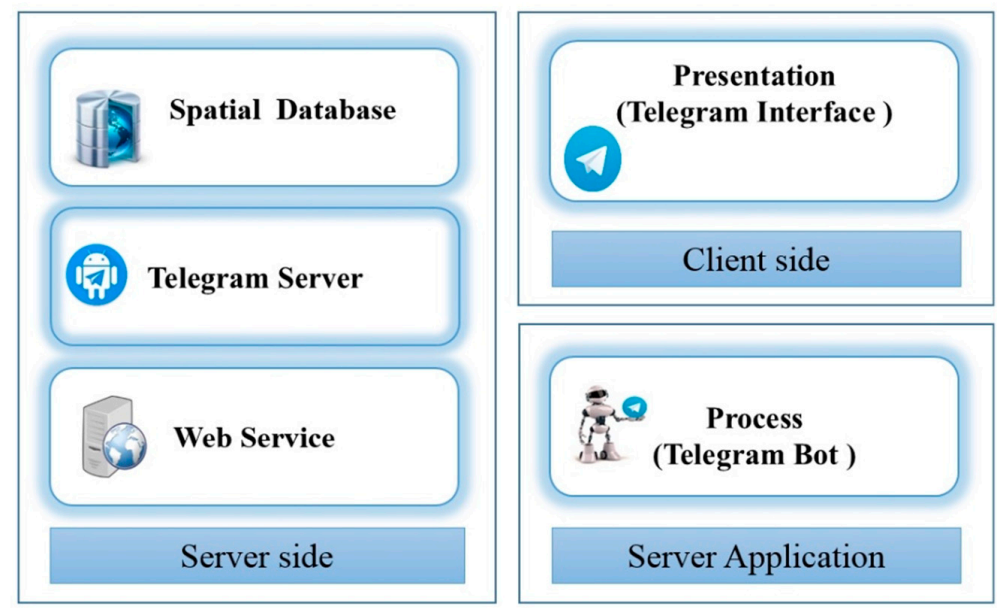

Figure 5. System architecture for the decision of urban services. 
The client side is the telegram application interface. This layer reads the data in the database according to the user's requests, and displays the appropriate map in the web browser. It was designed in the Visual Studio 2015 (C \#) programming environment.

The Server Application layer is an intermediate layer and it is the data processing task. This layer verifies the data entered in each step and then prepares them for executing the algorithm and generating messages sent to the user. In this layer, the Telegram application API is used to implement the robot. The server-side layer is the data layer. This layer stores and managed data. It consists of three sets: Web service that designed with PHP 5.2.0 programming language, Server Telegram and spatial database software that designed with PostgreSQL and PostGIS software.

\subsection{Graphical User Interface}

This study intends to design and implement a conceptual framework for collaborative web-based GIS for integration of different aspects of public facilities users. The PGIS framework integrated two components, including individual decision and group decision. Because the system is implemented in a social network environment, certainly, many users do not have enough knowledge and expertise in the field of geographic information systems. Therefore, a quite simple interface was designed.

The first part of the system is related to individual decision making. The user clicks on the bot name, @FuzzyMajorityModel. The user chooses the start option to communicate with the robot. In the next step, the user must enter personal information to log on to the individual decision. Then, user should select a fixed option scenario. A fixed option in the scenario is the number of places offered in the study area, and will be displayed in the form of a web-based map to the user.

The user must choose between these options at least two items and then send options to the system (Figure 6a). Next, the two main criteria and sub-criteria matrix containing them for weighting and binary comparison is shown. After the weighting, AHP operations are carried out on the performance of the system, and the survey takes place. The final output will be displayed in a web map. Figure $6 \mathrm{~b}$ shows a sample of the output of an individual decision. The second part of the system is the decision making group. By entering a username and password the main expert can be logged in (Figure 6c).

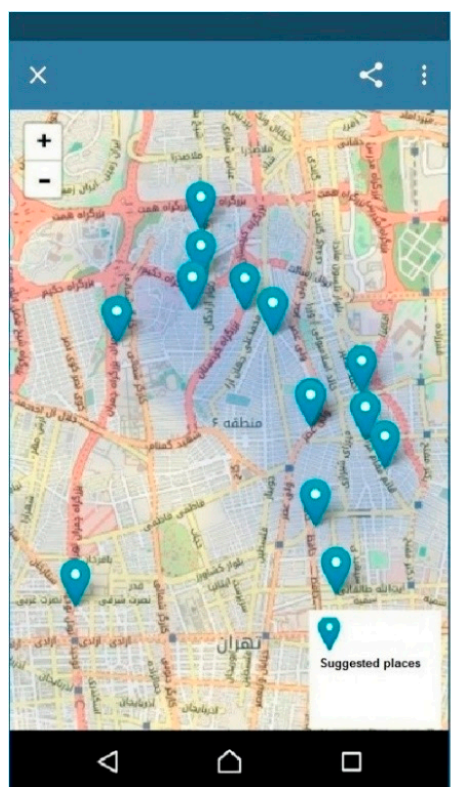

(a)

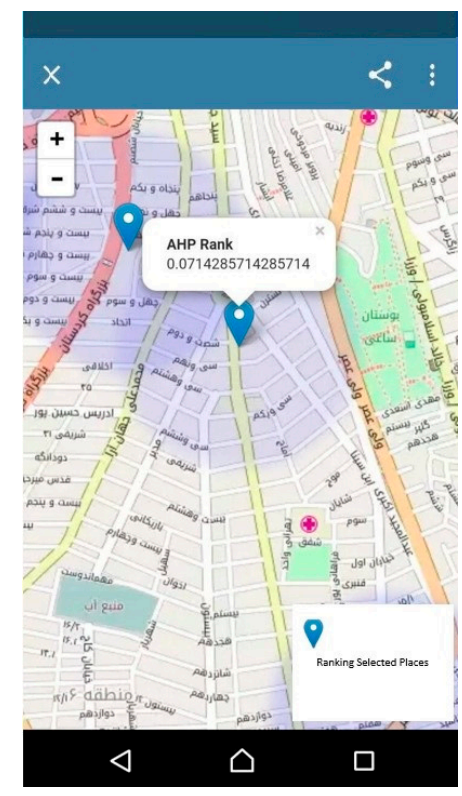

(b)

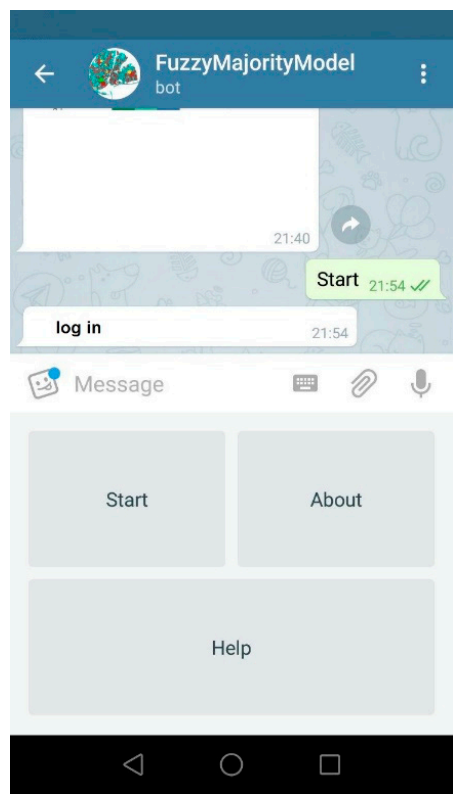

(c)

Figure 6. The sequence of system performance: (a) suggested options; (b) the output stage individual decision; and, (c) System manager panel. 
Figure 7 is an example of the output at this stage. Clicking on any point allows place priority value to be determined.

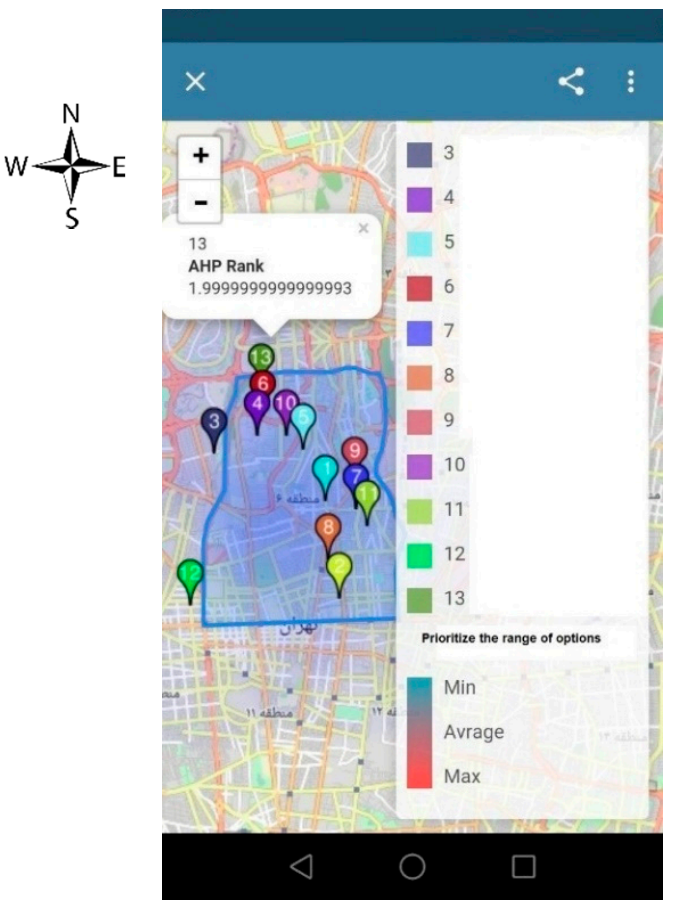

Figure 7. The result of group decision.

The evaluation process is completed in two stages; the system is first run only by 50 experts and then by three different levels of users, including 50 experts, 25 urban managers, and 150 pubic citizens, for the case study area via Telegram robot. Then, the archived results in both cases are compared with each other by 50 experts, 25 urban managers, and 150 pubic citizens. The selected locations for public parking are introduced to these test groups to ask their opinions according to tree evaluation factors including: "satisfaction", "distribution of public parking", and "suitability and ease-for-use".

The first part of the system shows the individual decision each of experts' and citizens' opinions of site selection for public parking; the second part is the collaborative decision making. Clearly, scenario\#2 is more applicable and appropriate for the site selection of public parking in the study area (Table 2).

Table 2. The evaluation results of comparison between two different modes of the system.

\begin{tabular}{ccccccc}
\hline \multirow{2}{*}{ Efficiency Indicator User } & \multicolumn{2}{c}{ Satisfaction } & \multicolumn{2}{c}{ Distribution of Public Parking } & \multicolumn{2}{c}{ Suitability and Ease-for-Use } \\
\cline { 2 - 7 } & Scenario\#1 & Scenario\#2 & Scenario\#1 & Scenario\#2 & Scenario\#1 & Scenario\#2 \\
\hline Experts & $85 \%$ & $75 \%$ & Appropriate & Appropriate & High & High \\
Citizens & $50 \%$ & $90 \%$ & Nearly-Appropriate & Very-Appropriate & Medium & High \\
Urban managers & $70 \%$ & $80 \%$ & Nearly-Appropriate & Appropriate & Medium & High \\
\hline
\end{tabular}

\section{Conclusions and Future Works}

The model presented herein is intended to facilitate site selection for public parking using a new approach of collaboration of multi-criteria decision-makers. Our setting is based on geo-social networks, due to the ease of access, user friendliness, and availability of spatial capabilities. The proposed method applied the analytic hierarchy process for weighting the criteria that was completed in two stages, once by 50 experts, and then by three different levels of users, including 50 experts, 25 urban managers, and 150 pubic citizens of the case study area. Then, the fuzzy majority method aggregated the archived results of AHP to determine the preferred locations that are suitable 
for public parking. The proposed method was implemented via Telegram robot. The evaluation of the proposed method is performed based on comparison of tow modes. The results justified two main advantages of the collaborative decision making scenario for solving public urban site selection: the fair distribution of the selected locations and the high satisfaction of the users.

This research has three main advantages: (1) the proposed framework is independent of application and it is performable for all public urban site selection. It is sufficient to introduce effective criteria to solve location problems; (2) the designed architecture and the implemented GUI via Telegram robot are free and accessible for every individual; and, (3) the uncertainty that stems from different opinions is modeled by fuzzy majority aggregation.

The results show that the user satisfaction of the citizens rose from $65 \%$ to $85 \%$, this is a meaningful reason to replace the proposed approach with the traditional method. Thus, our novel model may serve as a starting point for establishing a user-friendly tool for site selection of public parking. To generalize the proposed method, we suggest examining this setting in different geographic regions and other urban public site selection problems, such as shopping centers, heath care centers, and gas stations. A limitation of the model is that it implemented in the public space of an urban district, which is not familiar with spatial criteria. Effectively, this may decrease the accuracy of choices. Clearly, we recommend further investigation to develop an optimal model of site selection for urban facilities using geo-social networks.

Author Contributions: Zeinab Neisani Samani, conceived, designed and performed the experiments; Ali Asghar Alesheikh and Mohammad Karimi, analyzed the results and revised the paper.

Conflicts of Interest: The authors declare no conflict of interest.

\section{References}

1. LaGro, J.A., Jr. Site Analysis: Informing Context-Sensitive and Sustainable Site Planning and Design, 3rd ed.; Wiley: Hoboken, NJ, USA, 2013.

2. Eldrandaly, K.A. Developing a GIS-Based MCE Site Selection Tool in ArcGIS Using COM Technology. Int. Arab J. Inf. Technol. 2013, 10, 276-282.

3. Rikalovic, A.; Cosic, I.; Lazarevic, D. GIS Based Multi-Criteria Analysis for Industrial Site Selection. Procedia Eng. 2014, 69, 1054-1063. [CrossRef]

4. Veronesi, F.; Schito, J.; Grassi, S.; Raubal, M. Automatic selection of weights for GIS-based multicriteria decision analysis: Site selection of transmission towers as a case study. Appl. Geogr. 2017, 83, 78-85. [CrossRef]

5. Corda, A.F.; Roeßigerb, F.; Schwarza, N. Geocaching data as an indicator for recreational ecosystem services in urban areas: Exploring spatial gradients, preferences and motivations. Landsc. Urban Plan. 2015, 144, 151-162. [CrossRef]

6. He, R.; Ma, C.; Li, Y. Site selection of public parking lot in the new district. Int. J. Wirel. Mob. Comput. 2015, 8, 2. [CrossRef]

7. Chai, H.; He, R.; Ma, C.; Dai, C.; Zhou, K. Path Planning and Vehicle Scheduling Optimization for Logistic Distribution of Hazardous Materials in Full Container Load. Discret. Dyn. Nat. Soc. 2017, 2017, 9685125. [CrossRef]

8. Levinson, H.S. Zoning for Parking: A Global Perspective. J. Inst. Traffic Eng. 1984, 54, 18-22.

9. Boroushaki, S.; Malczewski, J. Participatory GIS: A Web-based Collaborative GIS and Multicriteria Decision Analysis. Urisa J. 2010, 22, 23-32.

10. Parker, C.-J.; May, A.; Mitchell, V. The role of VGI and PGI in supporting outdoor activities. Appl. Ergon. 2013, 44, 6886-6894. [CrossRef] [PubMed]

11. $\mathrm{Li}, \mathrm{Y} . ; \mathrm{Wu}, \mathrm{D} . ; \mathrm{Xu}, \mathrm{J}$; $\mathrm{Choi}, \mathrm{B} . ; \mathrm{Su}, \mathrm{W}$. Spatial-aware interest group queries in location-based social networks. Data Knowl. Eng. 2014, 92, 20-38. [CrossRef]

12. Malczewski, J.; Rinner, C. Multicriteria Decision Analysis in Geographic Information Science; Springer: Berlin/Heidelberg, Germany, 2015.

13. Hong, I. Spatial Analysis of Location-Based Social Networks in Seoul, Korea. J. Geogr. Inf. Syst. 2015, 7, 259-265. [CrossRef] 
14. Levy, N.; Benenson, I. GIS-based method for assessing city parking patterns. J. Transp. Geogr. 2015, 46, 220-231. [CrossRef]

15. Abbasi, O.R.; Alesheikh, A.A.; Sharif, M. Ranking the City: The role of Location-Based Social Networks in Collective Human Mobility Prediction. Int. J. Geo-Inf. 2017, 6, 5.

16. Krieg, J.-G.; Jakllari, G.; Toma, H.; Beylot, A.-L. Unlocking the smartphone's sensors for smart city parking. Pervasive Mob. Comput. 2018, 43, 78-95. [CrossRef]

17. Çetinkaya, C. Bike Sharing Station Site Selection for Gaziantep. Sigma J. Eng. Nat. Sci. 2017, 35, 535-543.

18. Malczewski, J. GIS and Multicriteria Decision Analysis; John Wiley and Sons: Etobicoke, ON, Canada, 1999.

19. Gao, H.; Liu, H. Data Analysis on Location-Based Social Networks. In Mobile Social Networking; Springer: New York, NY, USA, 2013; pp. 165-194.

20. Zheng, Y. Tutorial on location-based social networks. In Proceedings of the 21st International Conference on World Wide Web, Lyon, France, 16-20 April 2012.

21. Shang, S.; Guo, D.; Liu, J.; Zheng, K.; Wen, J.-R. Finding regions of interest using location based social media. Neurocomputing 2016, 173, 118-123.

22. Neysani Samany, N.; Delavar, M.R.; Chrisman, N.; Malek, M.R. An Ontology for Spatial Relevant Objects in a Location-aware System: Case Study: A Tourist Guide System. World Acad. Sci. Eng. Technol. Int. J. Comput. Inf. Eng. 2012, 63, 878-884.

23. Gazmeh, H.; Alesheikh, A.A.; Karimi, M.; Chehreghan, A. Spatio Temporal Forest Fire Spread Modeling Using Cellular Automata Honey Bee Foraging and GIS. Bull. Environ. Pharmacol. Life Sci. 2013, 3, 201-214.

24. Saaty, T. How to make a decision: The Analytic Hierarchy Process. Eur. J. Oper. Res. 1990, 48, 9-26. [CrossRef]

25. Pasi, G.; Yager, R.R. Modeling the concept of majority opinion in group decision-making. Inf. Sci. 2006, 176, 390-414. [CrossRef]

26. Yager, R.R. The power average operator. IEEE Trans. Syst. Man Cybern. 2001, 31, 724-731. [CrossRef]

27. Naserbakht, M. Application for the District 6 of Municipality of Tehran to become a Member of the International Safe Community Network. Available online: https:/ / isccc.global/files/custom/Community/ district_6.pdf (accessed on 26 February 2018).

(C) 2018 by the authors. Licensee MDPI, Basel, Switzerland. This article is an open access article distributed under the terms and conditions of the Creative Commons Attribution (CC BY) license (http:/ / creativecommons.org/licenses/by/4.0/). 